ORIENTAL JOURNAL OF CHEMISTRY

An International Open Free Access, Peer Reviewed Research Journal

www.orientjchem.org
ISSN: 0970-020 X

CODEN: OJCHEG

2015, Vol. 31, No. (1):

Pg. 489-491

\title{
Fatty Acid Profile of Acacia tortilis (Forssk.) Hayne Seed Oil Growing Wild in South of Iran
}

\author{
ZAHRA MOGHANLOO ${ }^{1}$, PARISA ZIARATI ${ }^{1}$ and JINOUS ASGARPANAH ${ }^{2 *}$ \\ ${ }^{1}$ Department of Medicinal Chemistry, Faculty of Pharmacy, Pharmaceutical \\ Sciences Branch, Islamic Azad University, Tehran - Iran (IAUPS). \\ Department of Pharmacognosy, Faculty of Pharmacy, Pharmaceutical Sciences \\ Branch, Islamic Azad University, Tehran - Iran (IAUPS). \\ ${ }^{*}$ Corresponding author E-mail: asgarpanah@iaups.ac.ir
}

http://dx.doi.org/10.13005/ojc/310159

(Received: December 01, 2014; Accepted: January 10, 2015)

\section{ABSTRACT}

The oil content and fatty acid composition of the mature seeds of Acacia tortiliscollected from natural habitat of the south of Iran were analyzed in order to determine their potential for human or animal consumption. The oil content in these edible seedswas found to be $4.1 \%$ based on the fresh weight. The oil was analyzed by GC and GC/MS. Three fatty acids and one triterpenewere identified which constituted $95.5 \%$ of the oil. The main fatty acid of the oil was linoleic acid $(70.0 \%)$.

Key words: Acacia tortilis, Seed oil, Linoleic acid.

\section{INTRODUCTION}

Acacia is a genus belonging to the Fabaceaefamily and comprises about 135 species of trees which are widely spread throughout the arid and semi-arid tropics ${ }^{1}$. A. tortilis, commonly known as umbrella thorn belongs to the sub family Mimosoideae. It is a medium umbrella-shaped tree with flat and glabrous pods. Aerial parts of $A$. tortilis are used as anthelmintic and antidiarrheal, and to treat asthma in folk medicine ${ }^{2}$. The seeds of some Acacia species were reported to be used as food and have been assessed for nutritional compositionsand were shown to contain considerable amount of $\mathrm{oil}^{3}$. As evident from literature, there was no phytochemical investigation on $A$. tortilis seed oil growing wild in south of Iran. Hence the current study includes extraction and characterization of $A$. tortilis seed oil to evaluate its oil potential and explore a new source of fatty acid for nutritional purposes.

\section{MATERIALSAND METHODS}

\section{Plant material}

A. tortilisseeds were collected in August 2014 from Sarkhun village, Bandar Abbas, Hormozgan Province, Iran: (27²3'34" N 56²3’59" 
E, 100m). Specimen was identified by R. Asadpour and voucher was deposited in the Herbarium of Faculty of Pharmacy, Pharmaceutical Sciences Branch, Islamic Azad University (IAUPS), Tehran under code number 1537-AUPF.

\section{Oil extraction}

Oil extraction was performedwith a Soxhlet apparatus using $n$-hexane as the solvent. $100 \mathrm{~g}$ of powdered seeds was extractedfor $6 \mathrm{~h}$ and then the solvent was evaporated by using a rotary evaporator at40 ÚC. The pure oil was transferred into a small glass vial,flushed with nitrogen and maintained at $18^{\circ} \mathrm{C}$ until analyzed for fatty acid composition.

\section{Preparation of fatty acid methyl esters}

Fatty acid methyl esters of the extracted oil wereprepared according to the method previously reported byMetcalfe et al. ${ }^{4}$. $1 \mathrm{~g}$ of the oil was weighed into a volumetric flask. Then, $25 \mathrm{ml}$ of 0.5 Nmethanolic potassium hydroxide was added and placed in the boiling water for $20 \mathrm{~min}$. Then $12 \mathrm{ml}$ boron trifluoride (BF3) was added and boiled again for $3 \mathrm{~min}$. After that, the flask was cooled and $5 \mathrm{ml}$ hexane and adequate saturated $\mathrm{NaCl}$ solution were added. The flask was shaken vigorously and left to stand for $5 \mathrm{~min}$. the fatty acid methyl esters were prepared and dissolved in $n$-hexane (the upper layer). $2 \mathrm{ml}$ of upper layer was transferred to a small vial and stored at0 ÚC until analyzed by GC/MS.

\section{Fatty acid analysis}

GC/MS was performed to determine the fatty acid composition of the oil.Fatty acid methyl esters analyses were performed on a Hp-6890 gas chromatograph (GC) equipped with a FID and a
DB-5 capillary column, $30 \mathrm{~m} \times 0.25 \mathrm{~mm}, 0.251 / 4 \mathrm{~m}$ film thickness, temperature programmed as follows: $60^{\circ} " 240^{\circ} \mathrm{C}$ at $4^{\circ} \mathrm{C} / \mathrm{min}$. The carrier gas was $\mathrm{N}_{2}$ at a flow of $2.0 \mathrm{ml} / \mathrm{min}$; injector port and detector temperature were $250^{\circ} \mathrm{C}$ and $300^{\circ} \mathrm{C}$, respectively. Sample was injected by splitting and the split ratio was 1:10.GC/MS analysis was performed on a Hewlett-packard $6890 / 5972$ system with a DB-5 capillary column $(30 \mathrm{~m} \times 0.25 \mathrm{~mm} ; 0.251 / 4 \mathrm{~m}$ film thickness. The operating conditions were the same conditions as described above but the carrier gas was $\mathrm{He}$. Mass spectra were taken at $70 \mathrm{eV}$. Scan mass range was from $40-400 \mathrm{~m} / \mathrm{z}$ at a sampling rate of $1.0 \mathrm{scan} / \mathrm{s}$. Quantitative data were obtained from the electronic integration of the FID peak areas. The components of the sample were identified by their retention time, retention indices, relative to $\mathrm{C}_{9}$ $\mathrm{C}_{40} n$-alkanes, computer matching with the WILEY275.L library and as well as by comparison of their mass spectra with those of authentic samples or with data already available in the literature ${ }^{5,6}$. The percentage of composition of the identified fatty acids was computed from the GC peaks areas without any correction factors and was calculated relatively.

\section{RESULTS AND DISCUSSION}

In this study, the fatty acid composition of A. tortilis seed oil native to south of Iran was determined. The oil extracted was viscous and yellow-green in color with the total oil content of $4.1 \%$. The quality of oil is mainly governed by the fatty acid composition hence the standardization of oil on the basis of fatty acid composition is mandatory.

Table 1: Fatty acid composition of $A$. tortilis seed oil.

\begin{tabular}{lllll}
\hline No. & Compound $^{\mathbf{a}}$ & $\mathbf{K l}^{\mathbf{b}}$ & $\mathbf{K l}^{\mathbf{c}}$ & \% \\
\hline 1 & Palmitic acid,methyl ester(16:0) & 1931 & 1927 & 20.6 \\
2 & Linoleic acid, methyl ester (18:2) & 2087 & 2092 & 70.0 \\
3 & Vaccenic acid, methyl ester (18:1) & 2111 & 2104 & 2.1 \\
4 & Squalene & 2779 & 2790 & 2.8 \\
& Total & & 95.5 & \\
\hline
\end{tabular}

\footnotetext{
${ }^{a}$ Compounds listed in order of elution.

${ }^{b} \mathrm{KI}$ (Kovats index) measured relative to $n$-alkanes $\left(\mathrm{C}_{9}-\mathrm{C}_{28}\right)$ on the non-polar DB- 5 column under condition listed in the Materials and Methods section. ${ }^{c} \mathrm{KI}$, (Kovats index) from literature.
} 
According to Table 1 seed oil consists mainly of essential saturated and unsaturated fatty acids. Linoleic acid (70.0\%) was found to be in maximum in $A$. tortilis seed oil, followed by palmitic acid $(20.6 \%)$ and vaccinic acid $(2.1 \%)$. Higher content of Linoleic acid in analyzed oil is noteworthy. Linoleic acid content in seed $(70.0 \%)$ is similar to sun-flower and safflower vegetable oils having specified codex standard range of $48 \%-74 \%$ and $67.6 \%-73.2 \%$ respectively ${ }^{2}$. Moreover, presence of the higher content of the saturated fatty acid palmitic acid $(20.6 \%)$ was expectable because the genus Acacia belongs to the family Fabaceae and being a legume species.Squalene was also identified with a considerable amount of $2.8 \%$ in the oil. It is atriterpene compound structurally similar to beta-carotene characterized as the intermediate metabolite in the synthesis of cholesterol. In humans, about $60 \%$ of dietary squalene is absorbed. Squaleneappears to function in the skin as an antioxidant and protect the human skin surface from lipid peroxidation due to exposure to UV and other sources of ionizing radiation. The primary therapeutic use of squalene currently is as an adjunctive therapy in a variety of cancers and it might be a useful addition to potentiate the effects of some cholesterol-lowering drugs ${ }^{\text {? }}$.

Literature survey revealed that there was just one phytochemical study on $A$. tortilis seed oil fatty acids ${ }^{2}$. Fatty acid composition of $A$. tortilis seed oil growing in India has been investigated previously. The oil content was reported a little lower (3.8\%) than that of the studied $A$. tortilis seeds. Linoleic content was reported much lower (36.7\%) than that of the studied oil. Presence of linolenic acid with high amount (50.4\%) and absence of it in the current oil was noticeable. Palmitic acid content in $A$. tortilis seed oil from Iran was much higher $(20.6 \%)$ than that of $A$. tortilis growing in India (6.4\%). Stearic acid and oleic acid were both reported in $A$. tortilis seed oil from India with so little amounts but they were not observed in the studied oil.

In conclusion he present study revealed that the seed oil of $A$. tortilis growing in south of Iran could be a new source of high linoleic-oleic acidrich edible oil and its full potential should be exploited. The use of oil from the seeds is of potential economic benefit to the poor native population of the areas where it is cultivated. The fatty acid composition of $A$. tortilis seed oil was very similar to that reported for commercially available edible vegetable oils like soybean, mustard, sunflower, groundnut and olive. Hence the seed oil of $A$. tortilis could be a new source of edible vegetable oil after the future toxicological studies.

\section{ACKNOWLEDGMENTS}

Supports from the Pharmaceutical sciences Branch, Islamic Azad University (IAUPS) are gratefully acknowledged.

\section{REFERENCES}

1. Pellew, A.R., The Production and Consumption of Acacia Browse and its Potential for Animal Protein Production, In: Browse in Africa, International Livestock Centre for Agriculture, Addis Ababa, (1980).

2. Srivastava, M.; Kumar, S. Food Nut. Sci. 2013, 4, 59-62.

3. Brown, A.J.; Cherikoff, V.; Roberts, D.C.K. Lipids. 1987, 22(7), 490-494.

4. Metcalfe, L.D.; Schmitz, A.A.; Pelka, J.R. Anal.
Chem. 1966, 38, 514-515.

5. Swigar, A.A., Silverstein, R.M., Monoterpenes. WI: Aldrich Chemical Company Publ., Milwaukee, USA (1981).

6. Adams, R.P., Identification of Essential Oil Components by Gas Chromatography/Mass Spectroscopy. Allured Publishing Co., Carol Stream, Illinois, (1995).

7. Kelly, G.S. Alter. Med. Rev. 1999, 4(1), 2936. 